\title{
Homoeologous GSL-ELONG gene replacement for manipulation of aliphatic glucosinolates in Brassica rapa L. by marker assisted selection
}

\author{
Arvind H. Hirani, Carla D. Zelmer, Peter B. E. McVetty, Fouad Daayf and Genyi Li*
}

The Department of Plant Science, University of Manitoba, Winnipeg, MB, Canada.

Edited by:

Qifa Zhang, Huazhong Agricultural

University, China

\section{Reviewed by:}

Xun Xu, BGI-Shenzhen, China

Xiyin Wang, Hebei United University,

China

\section{*Correspondence:}

Genyi Li, The Department of Plant Science, University of Manitoba, 66 Dafoe Road, Winnipeg, MB, Canada R3T2N2.

e-mail: genyi.li@ad.umanitoba.ca

\begin{abstract}
Aliphatic glucosinolates are the predominant sulfur-rich plant secondary metabolites in economically important Brassica crops. Glucosinolates and their hydrolysis products are involved in plant-microbe, plant-insect, plant-animal, and plant-human interactions. It is, therefore, important to manipulate glucosinolate profiles and contents in Brassica species. In this study, aliphatic glucosinolates were genetically manipulated through homoeologous recombination in backcross lines followed by marker assisted selection in B. rapa. A resynthesized $B$. napus line, from a cross between $B$. rapa and $B$. oleracea, was backcrossed with Chinese cabbage doubled haploid line, RI16. Marker assisted selection for non-functional gene was performed in each backcross generations. Advanced backcross progenies $\left(\mathrm{BC}_{3} \mathrm{~F}_{2}\right)$ were developed to identify homoeologous gene replacement and/or introgression. Reduction in $5 \mathrm{C}$ aliphatic glucosinolates (gluconapoleiferin, glucoalyssin, and glucobrassicanapin) was observed in $\mathrm{BC}_{3} \mathrm{~F}_{2}$ progenies of the recurrent parent that carried the GSL-ELONG ${ }^{-}$gene. The GSLELONG ${ }^{-}$positive backcross progenies were also screened by the A-genome and BraGSL-ELONG gene specific marker, which linked with $5 \mathrm{C}$ aliphatic glucosinolates. The A-genome specific marker was absent in the plants of advanced backcross progenies which showed reduction in $5 \mathrm{C}$ aliphatic glucosinolates. The results suggest that the functional allele had been replaced by the non-functional GSLELLONG ${ }^{-}$allele from $B$. oleracea. Some advanced backcross progenies $\left(\mathrm{BC}_{3} \mathrm{~F}_{2}\right)$ positive for the GSL-ELONG ${ }^{-}$allele and the A-genome specific SCAR marker BraMAM1-1 did not show reduction in $5 \mathrm{C}$ aliphatic glucosinolates, suggesting that GSL-ELONG ${ }^{-}$allele is recessive. Replacement of the functional locus in the A-genome by non-functional counterpart in the $\mathrm{C}$-genome reduced the content of $5 \mathrm{C}$ aliphatic glucosinolates in $\mathrm{B}$. rapa seeds with $20 \mu \mathrm{mol} / \mathrm{g}$.
\end{abstract}

Keywords: Brassica rapa, Brassica oleracea, homeologous recombination, SCAR markers, MAS, glucosinolates

\section{INTRODUCTION}

In the genus Brassica, three diploid species, B. rapa L., B. oleracea L., and B. nigra L. Koch, are the evolutionary original genome donors of three amphidiploid species B. napus L., $B$. juncea L. Czern. \& Coss., and B. carinata Br. These Brassica species are economically important crops and are cultivated for edible oil, industrial oil, and biodiesel. Since the introduction of Brassica species as crops in agricultural systems, many traits related to agronomy, morphology, physiology, yield, disease resistance, and end product quality have been improved. Most trait improvements have been achieved through conventional breeding approaches such as intraspecific and interspecific hybridization followed by selection. The development and analysis of alien chromosome addition lines were initiated in the 1990s for dissecting Brassica genomes for gene mapping and genetic analyses. Similarly, chromosome addition lines have also been deployed for the introgression of suitable traits from wild or weedy relatives to the existing cultivars. Alien chromosome addition monosomic and disomic lines have been successfully developed and proven to be useful resources for gene identification and chromosome homoeology studies between Brassica genomes of B. rapa $\times B$. oleracea, $B$. napus $\times B$. nigra, and $B$. rapa $\times B$. oxyrrhina (McGrath and Quiros, 1990; Hu and Quiros, 1991; Chen et al., 1992; Cheng et al., 1994; Srinivasan et al., 1998). Several agronomic, disease resistance, morphological, and quality traits such as erucic acid content, flowering time, seed coat color, and stem rot resistance have been successfully introgressed into cultivated Brassica crops through regular two parental crosses and subsequent backcrossing (Banga, 1988; Cheng et al., 1994; Navabi et al., 2010).

Wide hybridization requires formation of bivalents or multivalents between homoeologous chromosomes for recombination, which is highly affected by the genes that regulate pairing and homoeology of alien and host chromosomes. The mutant Ph1 gene, meiosis pairing regulator, resulted in synapsis and recombination between homoeologous chromosomes in wheat (Feldman, 1966; Martinez etal., 2001). Using the Ph1 mutant, several biotic and abiotic stress tolerance genes have been introgressed through interspecific crosses in cultivated wheat (King et al., 1997, Kuraparthy et al., 2009). 
On the other hand, Dover and Riley (1972) reported success of wide hybridization in wheat in the presence of a functional $\mathrm{Phl}$ locus. They suggested that several genes from Aegilops species suppressed the activity of the $P h 1$ gene during meiosis, which resulted in successful multivalent formation and subsequent homoeologous recombination. Similar meiotic regulatory mechanisms might be involved in interspecific or intergeneric Brassica crosses. In B. napus, a PrBn (Pairing Regulator in B. napus) gene located in the $\mathrm{C}$-genome of $B$. napus, is reported to be involved in the regulation of non-homologous cross over during meiosis (Jenczewski et al., 2003; Nicolas etal., 2009). Szadkowski et al. (2010) reported genome blending mechanism in the first meiosis of resynthesized B. napus by formation of bivalent and multivalent between homeologous chromosomes. In addition to that, genomic rearrangements including insertion and/or deletion of parental fragments and appearance of novel fragments reported in the second to fifth selfing generation of resynthesized $B$. napus (Song et al., 1995). Besides that, non-reciprocal translocation events are also observed in synthetic B. napus by Sharpe et al. (1995). Similarly, Gaeta et al. (2007) reported homeologous non-reciprocal translocations between the $\mathrm{A}$ - and $\mathrm{C}$-genome in early and subsequent advanced selfing generation of resynthesized $B$. napus. This suggests genome shuffling phenomenon in resynthesized $B$. napus creates genetic variability due to several recombination events and resulting phenotypic variations benefits breeders to genetically manipulate important traits such as, agronomic, disease resistance, and seed quality traits.

Glucosinolates, a class of nitrogen and sulfur containing plant secondary metabolites are found in Brassica species. Glucosinolates and their hydrolysis products are functionally associated with plants, microbes, insects, animals, and humans. Biosynthesis of glucosinolates occurs in three major steps namely, core-structure formation, side chain elongation, and side chain modification. Extensive studies on glucosinolates suggest that multi-gene family regulate these three steps of glucosinolate biosynthesis in the model plant Arabidopsis thaliana (Compos de Quiros et al., 2000; Kliebenstein etal., 2001a,c; Textor etal., 2007; Li et al., 2008). In B. rapa, BraGSL-ELONG gene family ortholog to AtMAM genes in Arabidopsis controls the side chain elongation steps of glucosinolate biosynthesis. Two genes (BoGSL-ELONG and BoGSL-PRO) are involved in side chain elongation, and a gene (BoGSL-ALK) is involved in side chain modification were identified and characterized in B. oleracea (Li and Quiros, 2002, 2003; Gao et al., 2004). Li and Quiros (2002) studied various accessions of $B$. oleracea for glucosinolate content and reported that white cauliflower produces $3 \mathrm{C}$ due to a functional BoGSL-PRO gene. On the other hand, lack of $4 \mathrm{C}$ aliphatic glucosinolates was due to a mutation at the splicing site of intron 3 of BoGSL$E L O N G$, leading to a non-functional gene in white cauliflower. In addition, they also reported that broccoli produced exclusively glucoraphanin, a $4 \mathrm{C}$ aliphatic glucosinolate, suggesting that broccoli has a non-functional BoGSL-ALK and a functional BoGSL-ELONG. Gene specific molecular markers were developed based on glucosinolate biosynthesis genes in B. oleracea for marker assisted selection to manipulate quality and quantity of aliphatic glucosinolates (Li and Quiros, 2002, 2003). Most recently, whole genome sequence of $B$. rapa spp. pekinensis $\mathrm{cv}$.
Chiifu-401-42 is publicly available with annotation of about 41000 genes (Wang et al., 2011, http://www.brassicadb.org). Sequenced genome information has opened an avenue for comparative analysis of genome with Arabidopsis for glucosinolate biosynthesis genes. Wang et al. (2011) reported over 100 orthologous genes for various steps of glucosinolate biosynthesis pathway in $B$. rapa, which revealed seven loci for BraGSL-ELONG genes for side chain elongation of aliphatic glucosinolates. Development and utilization of gene and/or loci specific molecular markers using sequenced genome would hasten marker assisted selection for improving quality traits like glucosinolates in Brassica vegetables and oilseeds.

In this study, we performed genetic manipulation of aliphatic glucosinolate profile and content in B. rapa through homoeologous gene replacement from $B$. oleracea (white cauliflower) using marker assisted selection. In this study, resynthesized B. napus lines were developed through interspecific hybridization between $B$. rapa and B. oleracea. Synthetic B. napus was backcrossed to B. rapa to develop B. rapa-B. oleracea chromosome addition lines harboring $B$. oleracea non-functional glucosinolate gene, GSL-ELONG ${ }^{-}$ through marker assisted selection. The Brassica A-genome possesses at least four loci of the BraGSL-ELONG gene involved in $4 \mathrm{C}$ and $5 \mathrm{C}$ aliphatic glucosinolate biosynthesis (Bisht et al., 2009). Based on this knowledge, marker assisted backcross breeding was performed to replace the functional BraGSL-ELONG ${ }^{+}$ locus/loci of $B$. rapa with the non-functional GSL-ELONG ${ }^{-}$ allele from B. oleracea to manipulate $4 \mathrm{C}$ and/or 5C aliphatic glucosinolates in this A-genome species. The advanced backcross families with the GSL-ELONG ${ }^{-}$gene were identified with gene specific markers and evaluated for glucosinolate profile and content.

\section{MATERIALS AND METHODS PLANT MATERIALS AND BACKCROSS BREEDING SCHEME}

A high glucosinolate content $B$. rapa double haploid (DH) line, RI16 was crossed with a B. oleracea white cauliflower accession Snowball 76 , and an embryo rescue technique was employed to produce resynthesized B. napus lines. The Chinese cabbage DH line, RI16 was derived from a hybrid cultivar, Summer Light 50 (Xiayang originally from Japan). One resynthesized B. napus line was backcrossed with $B$. rapa recurrent parent, Chinese cabbage (RI16) to produce backcross progenies. During recurrent backcrossing, marker assisted selection was performed in each generation with selection for genes of interest in the C-genome. In the first and second backcross cycle, recurrent parents were used as male parents. Additional reciprocal backcross was performed to enhance allosyndetical homoeologous recombination between the A-genome and alien chromosomes of B. oleracea. Advanced backcross progenies $\left(\mathrm{BC}_{3} \mathrm{~F}_{1}\right)$ were selfed to produce offspring homozygous for the replaced major glucosinolate gene GSL-ELONG- (Figure 1).

\section{DNA EXTRACTION AND C-GENOME SPECIFIC SCAR MARKER ASSISTED SELECTION}

For screening and selection, DNA was extracted from leaf tissues of 2 week old seedlings using a modified cetyltrimethylammonium bromide (CTAB) method described by Li and Quiros (2001). 


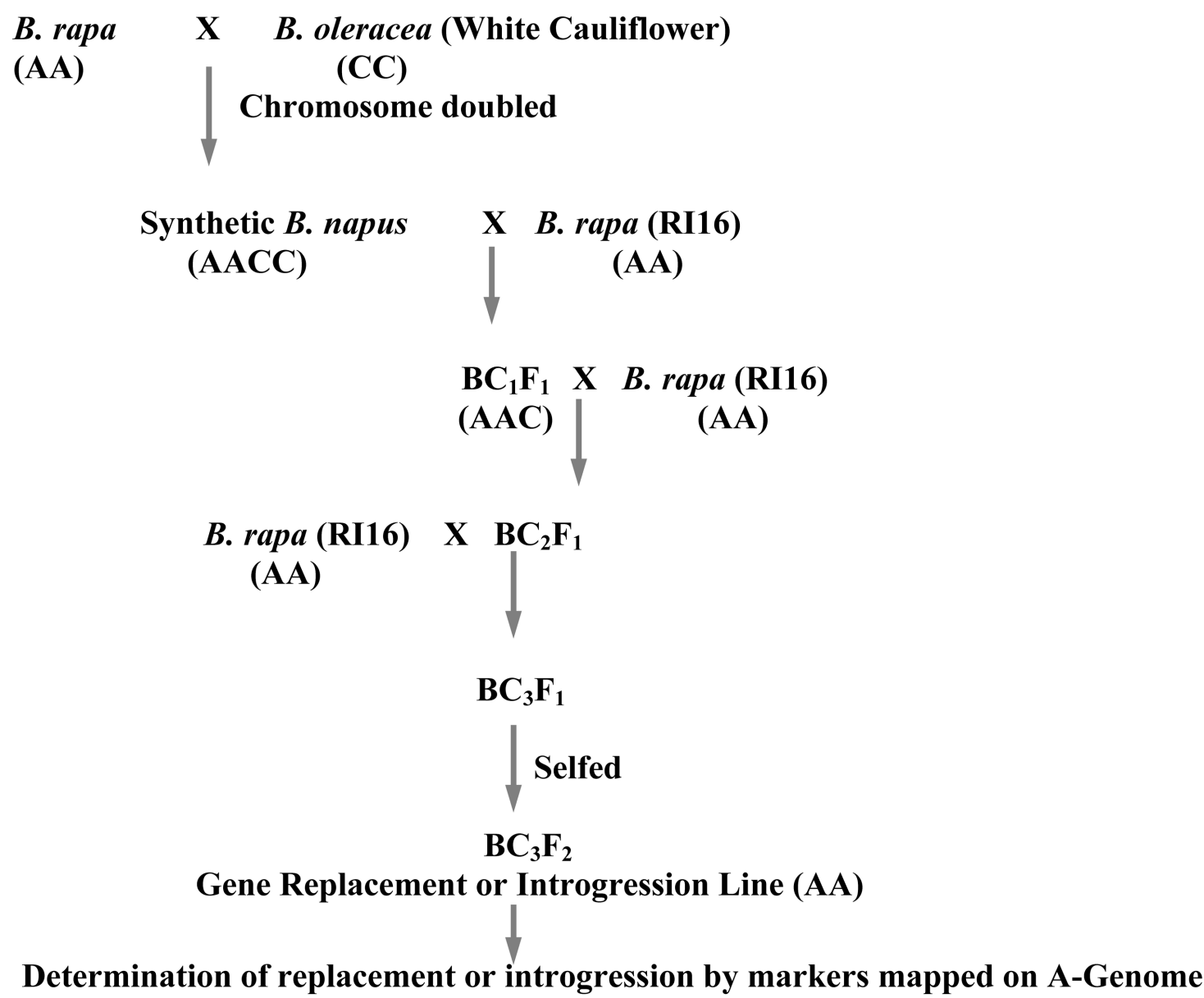

FIGURE 1 | Schematic diagram for introgression or replacement of glucosinolate genes in B. rapa from $B$. oleracea.

Instead of individual samples in Eppendorf tubes, 96 deep well plates were used. About $0.1 \mathrm{~g}$ leaf tissues from individual plants were placed in the wells and ground in liquid nitrogen. $500 \mu 12 \times$ CTAB buffer (2\% CTAB, 20 mM EDTA, $100 \mathrm{mM}$ Tris, $1.4 \mathrm{M} \mathrm{NaCl}$, $\mathrm{pH}$ 8.0) was added to each well and then samples were incubated at $65^{\circ} \mathrm{C}$ for $1.5 \mathrm{~h}$. Subsequently, $400 \mu \mathrm{l}$ chloroform was added to each well followed by vigorous mixing and centrifugation at $6200 \mathrm{rpm}$ for $10 \mathrm{~min}$. Ninety microliters of the supernatant was transferred to a 96-well plate and then DNA was precipitated with $50 \mu \mathrm{l}$ iso-propanol followed by centrifugation at $6200 \mathrm{rpm}$ for 5 min. The DNA pellet was washed with $70 \%$ ethanol, air dried

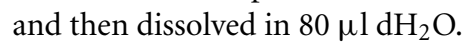

Marker assisted selection of non-functional BoGSL-ELONG $\left(G S L-E L O N G^{-}\right)$gene in backcross progenies were performed using the C-genome specific SCAR markers. The polymerase chain reaction (PCR) was conducted using the primer pairs PM25 + PM13 and IPM8 + IPM7 for GSL-ELONG- (Table 1).

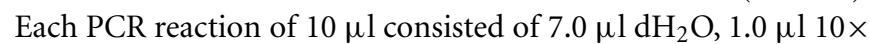
PCR buffer, $0.3 \mu l 50 \mathrm{mM} \mathrm{MgCl}_{2}, 0.15 \mu \mathrm{l} 25 \mathrm{mM}$ deoxyribonucleotide triphosphate (dNTP), $0.1 \mu \mathrm{l} \mathrm{Taq} \mathrm{polymerases,} 0.15 \mu \mathrm{l}$ $10 \mu \mathrm{M}$ forward and reverse primers and $2.5 \mu \mathrm{l}$ template DNA. The PCR program was $94^{\circ} \mathrm{C}$ for the initial $4 \mathrm{~min}$ to denature
Table 1 | List of primers used for backcross breeding and their sequence information and genome specificity.

\begin{tabular}{|c|c|c|c|}
\hline Gene (marker) & Primers & Sequence $\mathbf{5}^{\prime}-\mathbf{3}^{\prime}$ & Specificity \\
\hline GSL-ELONG ${ }^{-}$ & PM25 & CCTGTGAGACGTTAATACC & C-genome \\
\hline (PM25 + PM13) & PM13 & GAGCTTGAGTTCTATACGC & \\
\hline GSL-ELONG & IPM8 & CTTCGAGTAGACATCATGGA & C-genome \\
\hline (IPM8 + IPM7) & IPM7 & AAAGCTATTGTGCGAGGAC & \\
\hline GSL-ELONG ${ }^{+}$ & Br-MAM1-1F & GTTTCCCTGCGTCATCAGA & A-genome \\
\hline (BraMAM1-1) & Br-MAM1-1R & CTAAGCTCTTCGCATAGCTA & \\
\hline GSL-ELONG ${ }^{+}$ & AE2F & CAGTCAAATTTACCGCCTT & A-genome \\
\hline (BraAE2) & AE2R & GGTGGCTTTCGCGGACAC & \\
\hline
\end{tabular}

genomic DNA followed by 35 cycles of $94^{\circ} \mathrm{C}$ for $1 \mathrm{~min}, 55^{\circ} \mathrm{C}$ for $1 \mathrm{~min}$ and $72^{\circ} \mathrm{C}$ for $1.5 \mathrm{~min}$. For all backcross generations, the GSL-ELONG- ${ }^{-}$gene specific SCAR markers were scored on 1.2\% agarose gels. One to seven plants from each family were selected using SCAR markers for the next backcross with the recurrent parents. 


\section{LEAF AND SEED GLUCOSINOLATE EXTRACTION}

Leaf glucosinolate was extracted from early $\left(\mathrm{BC}_{1} \mathrm{~F}_{1}\right)$ and advanced $\left(\mathrm{BC}_{3} \mathrm{~F}_{1}\right)$ backcross progenies to determine glucosinolate profiles. Glucosinolate analysis was performed on $\mathrm{BC}_{3} \mathrm{~F}_{2}$ seeds from the plants positive for the C-genome SCAR markers. Total glucosinolate content was extracted from $200 \mathrm{mg}$ air dried seeds and $250 \mathrm{mg}$ fresh young leaf tissues. Leaf and seed glucosinolate purification and overnight desulfation reactions were performed using sephadex (Sigma-Aldrish, Canada) and purified sulfatase from Helix pomatia (Sigma-Aldrish, Canada) as described by Kliebenstein et al. (2001b) with some minor modifications. Final desulfoglucosinolates were eluted into $400 \mu \mathrm{l}$ distilled water: $70 \%$ methanol (1:1 v/v).

\section{DETECTION AND QUANTIFICATION OF ALIPHATIC GLUCOSINOLATES IN BACKCROSS PROGENIES}

Leaf and seed desulfoglucosinolate separation and quantification was performed in a 5- $\mu \mathrm{m}$ column (LichroCART ${ }^{\circledR}$ 250-4 RP18, Fisher Scientific, Ottawa, Canada) coupled with the Alliance ${ }^{\circledR}$ reverse phase high-performance liquid chromatography (HPLC; Waters 2695) and photodiode array detector (Waters 996) system (Waters, MA, USA). Desulfoglucosinolates were separated using mobile phase HPLC grade methanol (A) and distilled water (B) at a flow rate of $1 \mathrm{ml} / \mathrm{min}$. Both solvents were set up at gradients of an 8-min 7:93 A/B (v/v), a 4-min 15:85 A/B (v/v), an 18-min 55:45 A/B (v/v), a 5-min 92:8 A/B (v/v), a 5-min 92:8 A/B (v/v), a 5-min 1.5:98.5 A/B (v/v), a 3-min 1.5:98.5 A/B (v/v), and final 4-min $0: 100 \mathrm{~A} / \mathrm{B}(\mathrm{v} / \mathrm{v})$ with total running time of $52 \mathrm{~min}$. Individual glucosinolates were identified according to retention times and quantity was calculated in micromoles per gram and adjusted with relative response factors as described by Brown et al.(2003; Table 2).

\section{DETERMINATION OF GENE REPLACEMENT THROUGH THE A-GENOME SPECIFIC MARKERS}

The A-genome and BraGSL-ELONG gene specific SCAR markers (Table 1) for the glucosinolate side chain elongation were used to determine replacement of major effect locus/loci in $B$. rapa. Advanced backcross progenies were screened with the Agenome specific BraMAM1-1 and BraAE2 SCAR markers. These SCAR markers are dominant markers; therefore, absence of band was considered evidence of putative replacement/transposition of the native allele(s) with the corresponding allele from the C-genome.

\section{CYTOLOGICAL ANALYSIS OF CHROMOSOMES}

Chromosomes were counts in $\mathrm{BC}_{3} \mathrm{~F}_{3}$ plants from those lines which reduced $5 \mathrm{C}$ aliphatic glucosinolates. Flower buds were fixed for $24 \mathrm{~h}$ in propionic acid : absolute ethanol $(1: 3 \mathrm{v} / \mathrm{v})$ and ferric chloride $(\sim 0.03 \%)$ was added as a mordant. Subsequently, buds were rinsed and stored in 70\% ethanol. Flower buds were dissected and anthers were squashed in a drop of $1 \%$ acetocarmine on a glass slide. For chromosome counting, 10-20 pollen mother cells (PMCs) per flower bud, at least one bud per plant and two to four plants per lines were examined.

\section{RESULTS \\ CROSSABILITY OF DIGENOMIC TRIPLOID HYBRID WITH RECURRENT B. rapa}

A resynthesized $B$. napus line was developed by a cross between $B$. rapa genotype (high glucosinolate content) and $B$. oleracea white cauliflower genotype (lack of $4 \mathrm{C}$ and $5 \mathrm{C}$ aliphatic glucosinolate content). The resynthesized B. napus line was backcrossed with B. rapa DH line RI16 of Chinese cabbage. The recurrent parent Chinese cabbage had distinct glucosinolate profile and content. The Chinese cabbage line produced gluconapin and trace amounts of progoitrin as $4 \mathrm{C}$ glucosinolates together with glucoalyssin and glucobrassicanapin as $5 \mathrm{C}$ aliphatic glucosinolates. Crossing of the resynthesized B. napus line with the B. rapa recurrent parent, RI16, on average, produced four seeds per silique (2-8), and resulted in digenomic triploid hybrid (AAC) plants. These AAC hybrid plants were subsequently backcrossed with the same $B$. rapa recurrent parent. In the case of the second backcross $\left(\mathrm{BC}_{2} \mathrm{~F}_{1}\right)$, on average, three seeds per silique $(0-5)$ were recorded. Seed setting in $\mathrm{BC}_{2}$ hybrids were very low, about $40 \%$ silique did not produce seeds, apparently due to genomic irregularities in the plants. Positive plants $\left(\mathrm{BC}_{2} \mathrm{~F}_{1}\right)$ for the $\mathrm{C}$-genome specific SCAR markers were selected and reciprocally backcrossed to the RI16 to produce $\mathrm{BC}_{3} \mathrm{~F}_{1}$ seeds. In $\mathrm{BC}_{3} \mathrm{~F}_{1}$ progenies, normal seed setting was observed, it could be due to reciprocal cross conducted that recovered recurrent genome and eliminated extra chromosomes from the genome. The C-genome specific SCAR marker positive plants

Table 2 | List of glucosinolates with their trivial and chemical names and numbers of side chain carbons.

\begin{tabular}{llll}
\hline Trivial name & Peak no. & Chemical name & \#C in side chain \\
\hline Progoitrin (Pro) & 1 & 2-Hydroxybutenyl & $4 C$ \\
Sinigrin (Sin) & 2 & 2-Propenyl & $3 \mathrm{C}$ \\
Gluconapoleiferin (Gnapol) & 3 & 2-Hydroxy-4-pentenyl & $5 \mathrm{C}$ \\
Glucoalyssin (Galy) & 4 & 5-Methylsulfinylpentyl & $5 \mathrm{C}$ \\
Gluconapin (Gnap) & 5 & 3-Butenyl & $4 \mathrm{C}$ \\
4-Hydorxyglucobrassicin (4OH) & 6 & 4-Hydorxyglucobrassicin & Indole \\
4-Methoxyglucobrassicin (4MGB) & 7 & 4-Methoxyglucobrassicin & Indole \\
Glucobrassicanapin (Gbnap) & 8 & 4-Pentenyl & $5 \mathrm{C}$ \\
Total alipahtic GSL (Tagsl) & - & Sum of aliphatic GSL & $3 \mathrm{C}+4 \mathrm{C}+5 \mathrm{C}$
\end{tabular}


(30\%) were selfed to produce homozygous progenies $\left(\mathrm{BC}_{3} \mathrm{~F}_{2}\right)$. Seed setting was normal in all the homozygous progenies of $\mathrm{BC}_{3} \mathrm{~F}_{1}$.

\section{GENOME SPECIFIC SCAR MARKERS FOR ALIPHATIC GLUCOSINOLATES}

The C-genome specific SCAR markers PM25 + PM13 and IPM8 + IPM7 were used to screen for GSL-ELONG ${ }^{-}$gene in marker assisted selection of backcross progenies (Figure 2). All backcross generations $\left(\mathrm{BC}_{1} \mathrm{~F}_{1}\right.$ to $\left.\mathrm{BC}_{3} \mathrm{~F}_{2}\right)$ were screened with gene specific SCAR markers to obtain positive plants (Table 3). Marker positive plants in $\mathrm{BC}_{1} \mathrm{~F}_{1}$ to $\mathrm{BC}_{3} \mathrm{~F}_{1}$ could be due to the presence of the $\mathrm{C}$-genome addition chromosome or due to the replacement or introgression of a C-genome fragment containing the GSL$E L O N G^{-}$gene into the A-genome. In the backcross generations, loss of both the C-genome specific SCAR markers (PM25 + PM13 and IPM8 + IPM7) was observed in $\mathrm{BC}_{1}$ (six families), $\mathrm{BC}_{2}$ (four families), and $\mathrm{BC}_{3}$ (six families). The loss of these markers could be due to disappearance of additional chromosome without introgression and/or replacement events. On the other hand, four families in $\mathrm{BC}_{1}$, three families in $\mathrm{BC}_{2}$, and four families in $\mathrm{BC}_{3}$ were detected with the C-genome specific markers for GSL$E L O N G^{-}$gene. This suggests that homoeologous recombination events might had occurred and resulted in replacement or introgression of the chromosomal fragments of the C-genome into the A-genome. There are three possibilities for the C-genome specific SCAR marker behavior, (i) replacement with the A-genome fragment, (ii) introgression of the $\mathrm{C}$-genome fragment into the A-genome, and (iii) existence of additional chromosome in the backcross progenies (aneuploid). The A-genome specific SCAR markers for GSL-ELONG ${ }^{+}$loci of chromosome A3 (BraMAM1-1) and chromosome $\mathrm{A} 2$ (BraAE2) were used to screen the $\mathrm{BC}_{3} \mathrm{~F}_{2}$ population of the recurrent parent RI16 to investigate the occurrence of gene replacement or introgression. Fifteen $\mathrm{BC}_{3} \mathrm{~F}_{2}$ plants of this population did not show the A-genome specific marker BraMAM1-1 for GSL-ELONG ${ }^{+}$locus of chromosome A3, suggesting that homoeologous recombination and gene replacement had occurred. On the other hand, eight $\mathrm{BC}_{3} \mathrm{~F}_{2}$ families displayed both the A- and C-genome specific markers, suggesting that introgression of GSL-ELONG ${ }^{-}$in the A-genome had occurred. However, no phenotypic changes in leaf and seed glucosinolates were observed in these families.

\section{MODIFICATION OF ALIPHATIC GLUCOSINOLATE PROFILES IN BACKCROSS PROGENIES}

Two parental lines, RI16 (B. rapa) containing $37 \mu \mathrm{mol} / \mathrm{g}$ seed $4 \mathrm{C}$ and $19 \mu \mathrm{mol} / \mathrm{g}$ seed $5 \mathrm{C}$ aliphatic glucosinolates and Snowball 76 (B. oleracea) containing $72 \mu \mathrm{mol} / \mathrm{g}$ seed $3 \mathrm{C}$ and trance amount of $4 \mathrm{C}$ and $5 \mathrm{C}$ aliphatic glucosinolates were used to develop resynthesized $B$. napus line containing $52 \mu \mathrm{mol} / \mathrm{g}$ seed $4 \mathrm{C}$ and $8 \mu \mathrm{mol} / \mathrm{g}$ seed 5C aliphatic glucosinolates. Total aliphatic glucosinolate contents in seeds of B. rapa (RI16), B. oleracea (Snowball 76) and resynthesized $B$. napus line were 56, 74, and $60 \mu \mathrm{mol} / \mathrm{g}$, respectively (Table 4 ).

Fifty $\mathrm{BC}_{3} \mathrm{~F}_{2}$ plants positive for GSL-ELONG ${ }^{-}$markers were selected for glucosinolates analysis. A total 15 plants (30\%) were found to have reduced $5 \mathrm{C}$ aliphatic glucosinolates by five times to their recurrent parent RI16n and all these plants did not show the A-genome specific marker BraMAM1-1 corresponding to GSL$E L O N G+$ locus responsible for the biosynthesis of $5 \mathrm{C}$ aliphatic glucosinolates (Figures 3 and 4). On the other hand, 35 plants (70\%) which were positive for the GSL-ELONG ${ }^{-}$marker did not

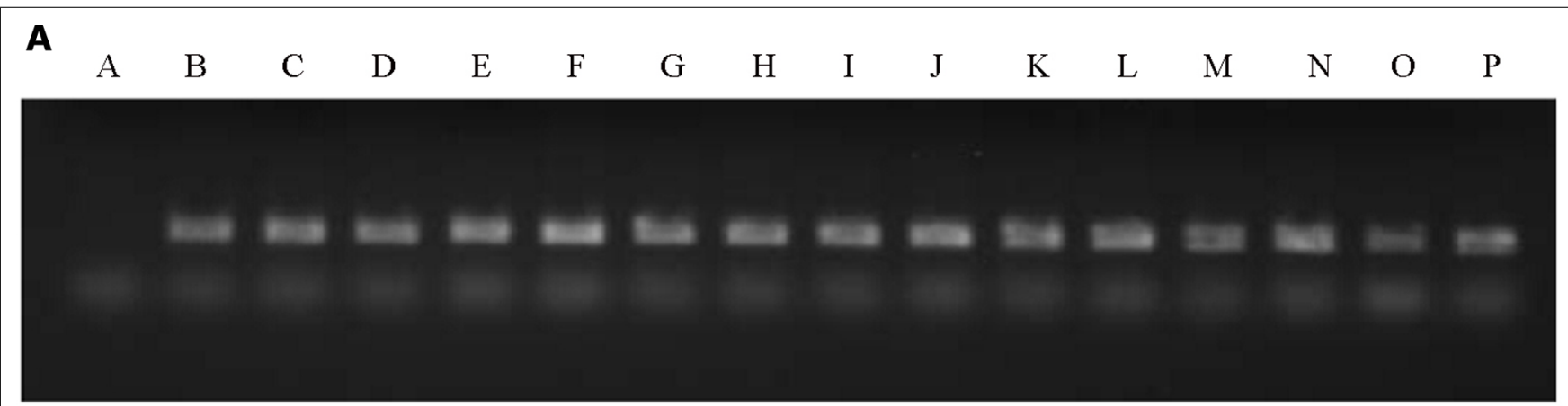

B

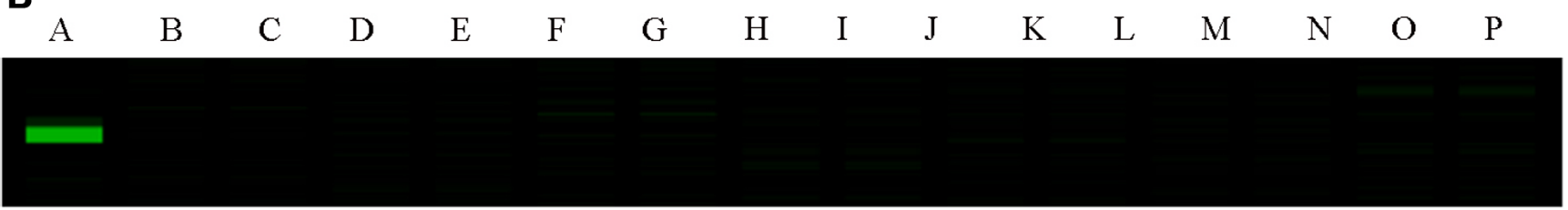

FIGURE 2 | Polymerase chain reaction (PCR) gel image of GSL-ELONG- / GSL-ELONG+ locus, in the parental lines RI16, white cauliflower and selected backcross progenies of $\mathbf{B C}_{\mathbf{3}} \mathbf{F}_{\mathbf{2}}$. A-RI16 (B. rapa), B-white cauliflower (B. oleracea), $\mathrm{C}$ to $\mathrm{P}$ - selected backcross progenies of $\mathrm{BC}_{3} \mathrm{~F}_{2}$. (A) C-genome and GSL-ELONG ${ }^{-}$gene specific SCAR marker, PM25 + PM13 (B) A-genome and GSL-ELONG ${ }^{+}$gene specific SCAR marker, BraMAM1-1. 
Table 3 | Aliphatic glucosinolate contents in parental lines B. rapa (RI16), B. oleracea (Snowball 76), and synthetic B. napus (RI16 $\times$ Snowball 76).

\begin{tabular}{|c|c|c|c|c|c|c|c|c|c|}
\hline B. rapa $(\mathrm{R} \mid 16)$ & 0.65 & 1.74 & 0.32 & 2.73 & 36.21 & 15.45 & 37.02 & 18.51 & 55.52 \\
\hline B. napus (synthetic line) & 24.57 & 0.70 & 0.85 & 1.36 & 27.39 & 5.10 & 51.96 & 7.31 & 59.27 \\
\hline
\end{tabular}

show any changes in glucosinolate profiles due to the existence of corresponding functional alleles of the A-genome. The recurrent parent Chinese cabbage RI16 produced $20 \mu$ mole/g seed of $5 \mathrm{C}$ aliphatic glucosinolates, whereas some of the backcross progenies of RI16 produced trace amount ( $<5 \mu \mathrm{mol} / \mathrm{g}$ seed) of $5 \mathrm{C}$ aliphatic glucosinolates (Figures 3 and $\mathbf{4}$ ). The backcross progenies, which reduced 5C aliphatic glucosinolates were increased $4 \mathrm{C}$ aliphatic glucosinolates, resulting $4 \mathrm{C}$ glucosinolates represent total aliphatic glucosinolates in those progenies (Figure 5). Results of the A- and $\mathrm{C}$-genome specific molecular markers and modification of glucosinolate profiles indicate possible functional gene replacement by non-functional alleles.

Further to validate molecular marker results, chromosomes were counted in $\mathrm{BC}_{3} \mathrm{~F}_{3}$ plants which reduced $5 \mathrm{C}$ aliphatic glucosinolates. Two to four plants from each $\mathrm{BC}_{3} \mathrm{~F}_{2}$ lines were analyzed for chromosome numbers. All PMCs showed normal cell divisions during meiosis and did not show any univalent or lagging chromosomes suggesting that all plants contained 20 chromosomes (Figure 6).

\section{DISCUSSION}

Glucosinolate composition and quantity are genetically regulated quantitative traits in Arabidopsis and Brassica species. B. rapa has a high level of genome duplication, which results in more loci with various functional properties (Punjabi et al., 2008). Genome duplications and rearrangements in $B$. rapa have led to a very complex genetic basis for glucosinolate biosynthesis. B. rapa and B. oleracea diverged quite recently (approximately 7.9 MYA) from a common ancestor when compared to B. nigra (approximately between 16 and 18 MYA), therefore, relatively high homoeology exists between the A- and C-genomes (Parkin et al., 1995, 2005; Wroblewski et al., 2000; Punjabi et al., 2008). High homoeology between the A- and C-genomes permits crossing over and recombination events in the crosses of the $\mathrm{A}$ - and $\mathrm{C}$-genome holding Brassica species.

Chromosomal pairing and recombination between homoeologous chromosomes in digenomic triploid (AAC) lines of $B$. rapa $\times$ B. oleracea occurs (Attia and Röbbelen, 1986, 1987), however, a very low rate of homoeologous recombination was

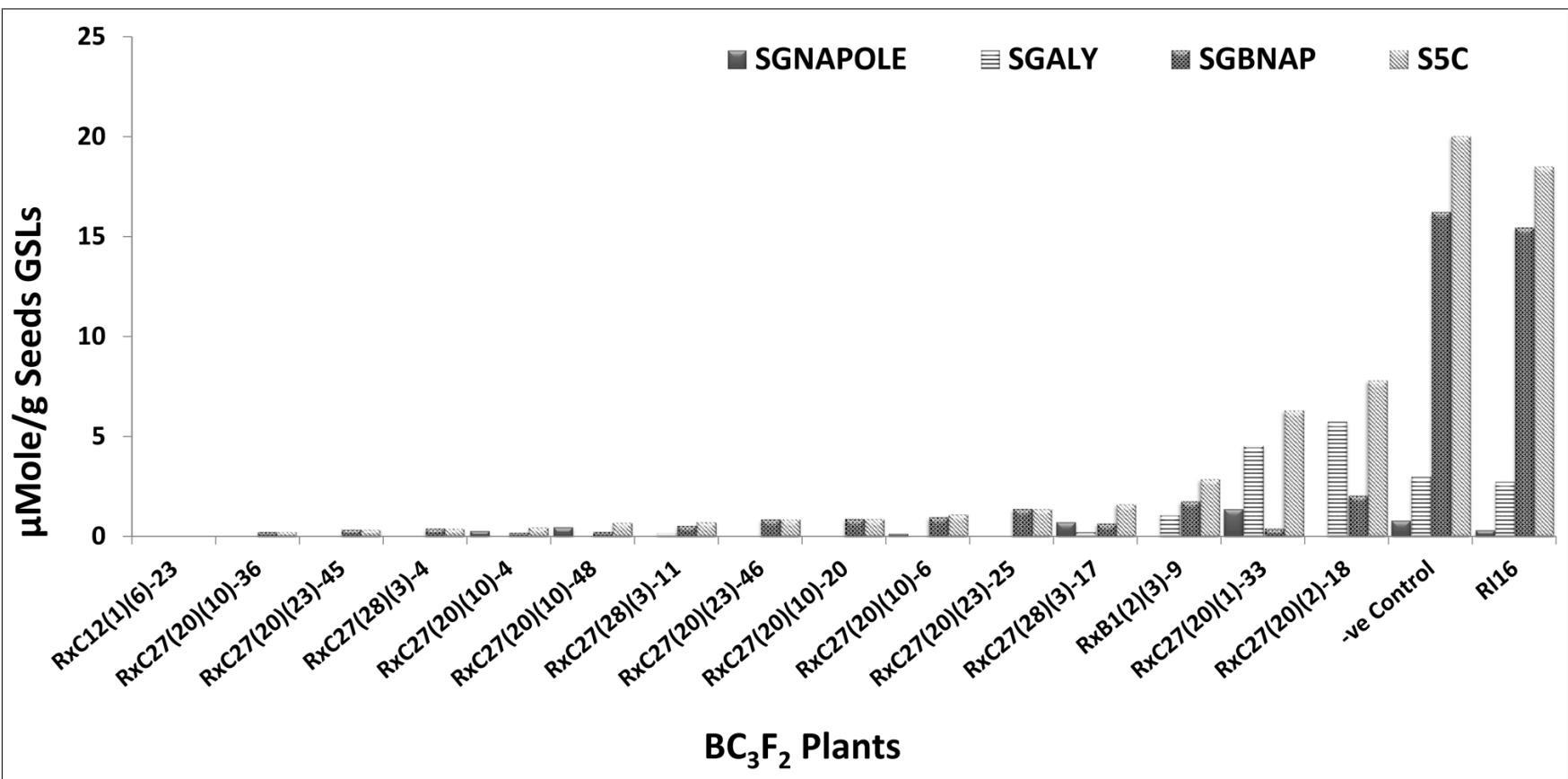

FIGURE 3 | $\mathbf{B C}_{\mathbf{3}} \mathbf{F}_{\mathbf{2}}$ plants of RI16 recurrent parent with reduction in $\mathbf{5 C}$ aliphatic glucosinolates in seeds. SGNAPOLE, seed gluconapoleiferin; SGALY, seed glucoalyssin; SGBNAP, seed glucobrassicanapin; S5C, seed sum of aliphatic 5 C glucosinolates. 
Table 4 | GSL-ELONG- (PM25 + PM13 and IPM8 + IPM7) marker transmission frequency in interspecific backcross progenies ${ }^{\S}$.

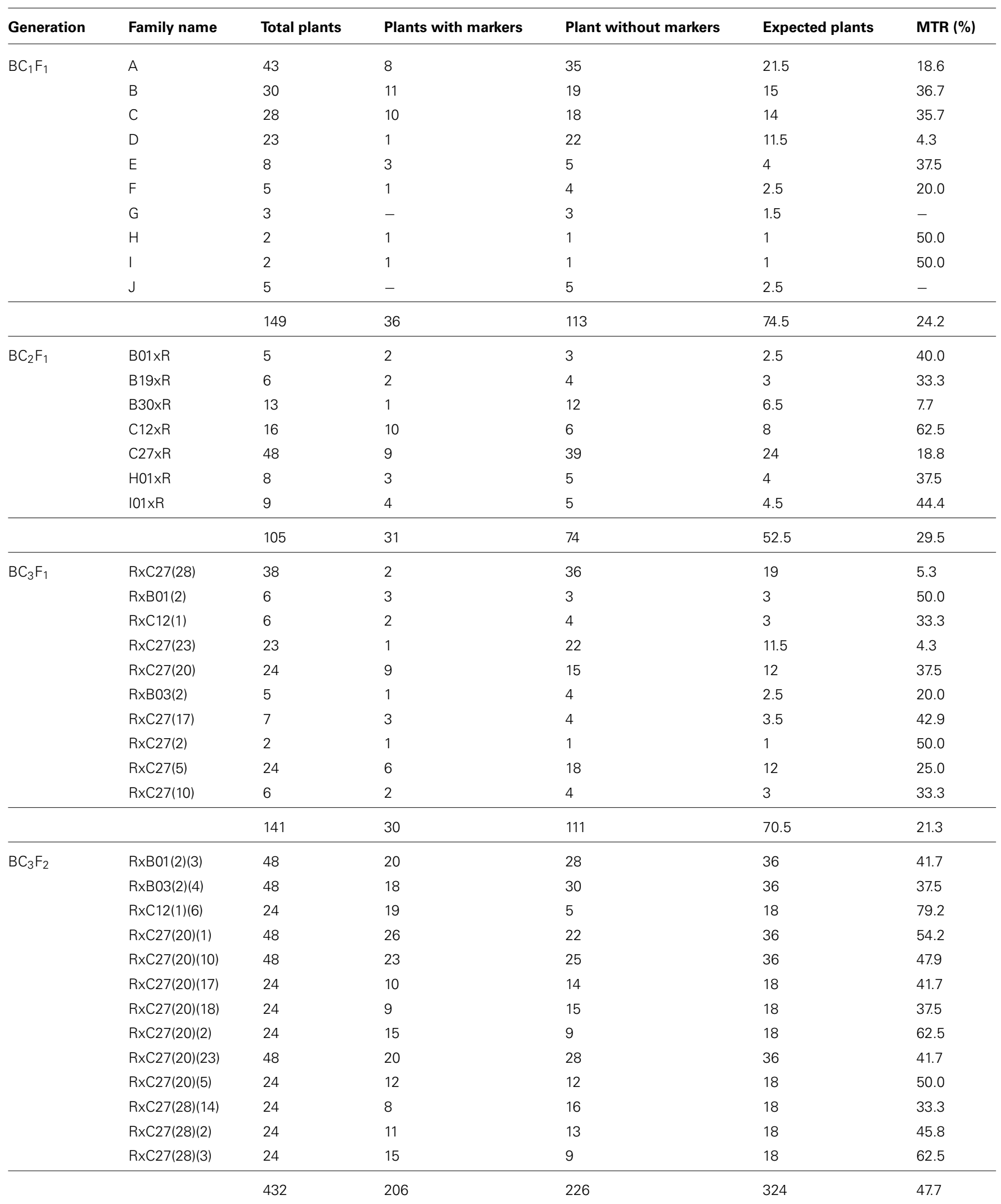

$\S$ Resynthesized B. napus $\times$ B. rapa hybrid, recurrently backcrossed to B. rapa; $R$-R/16. Those backcross lines, which lost C-genome specific marker has not proceeded to next generation. 

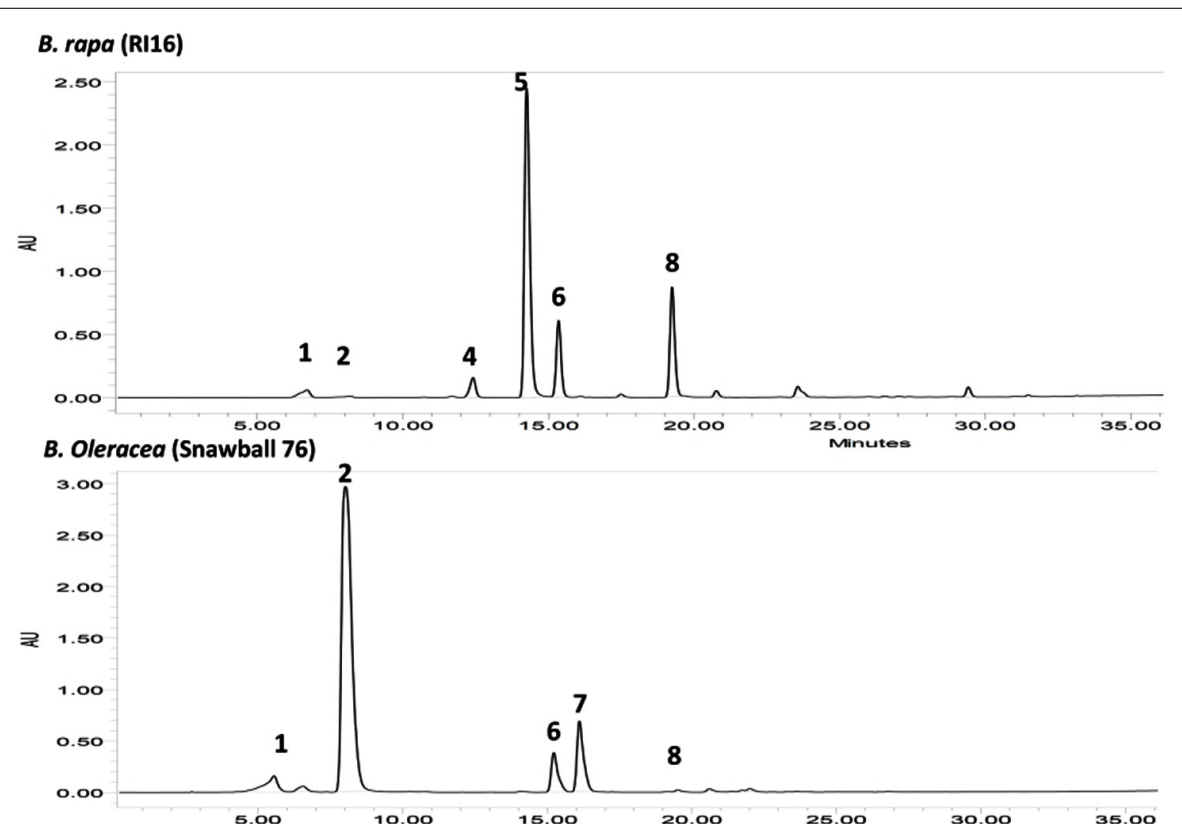

Synthetic B. Napus
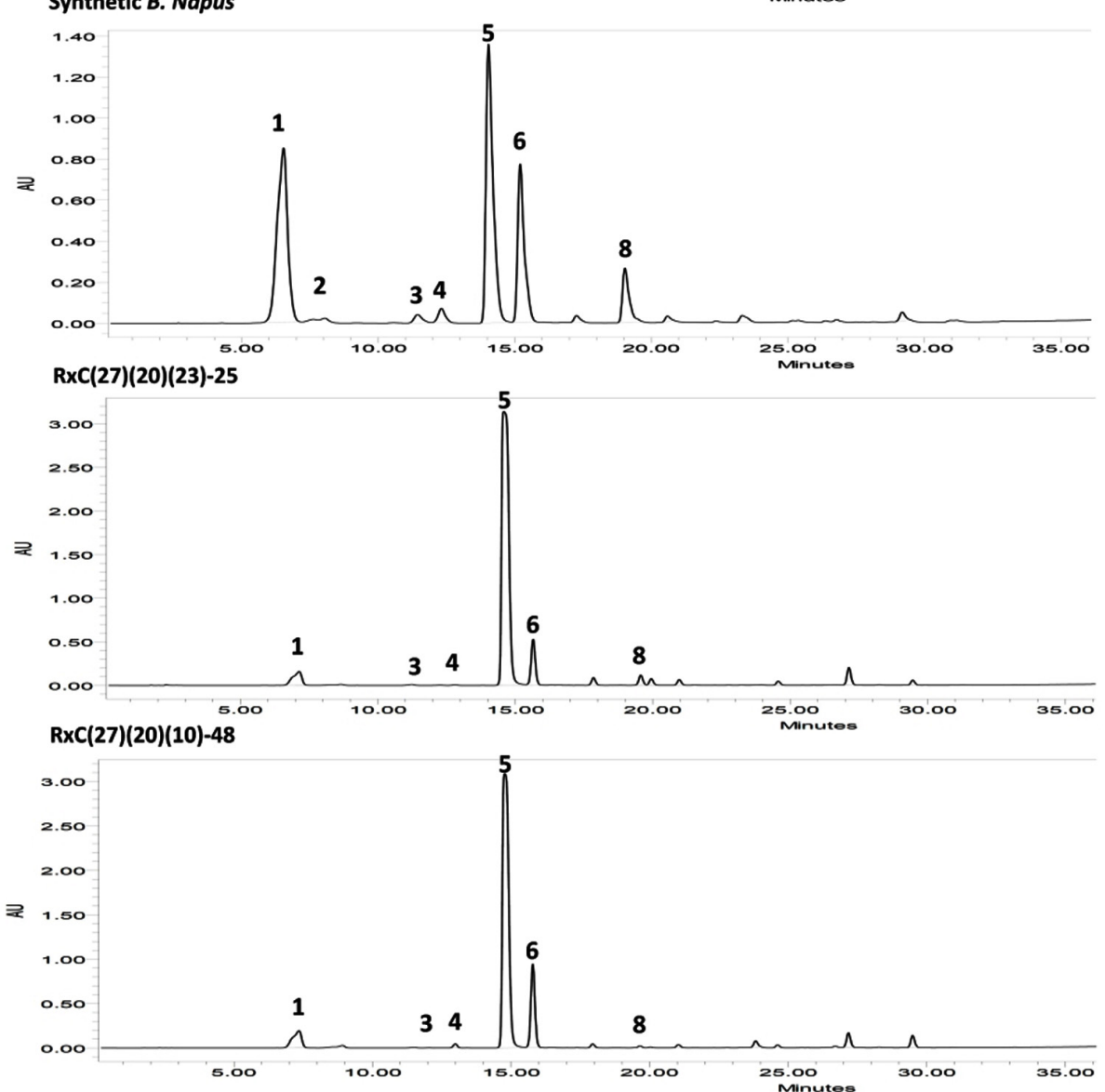

FIGURE 4 | High-performance liquid chromatography (HPLC) profiles of seed glucosinolates in parental lines $B$. rapa (RI16), $B$. oleracea (Snowball 76), resynthesized $B$. napus, and advanced backcross progenies, $\mathrm{RxC27(20)(23)-25}$ and $\mathrm{RxC27(20)(10)-48;} \mathrm{Peak} 1$ Progoitrin, Peak 2 Sinigrin, Peak 3 Gluconapoleiferin, Peak 4 Glucoalyssin, Peak 5

\section{Gluconapin, Peak 6 4-Hydroxyglucobrassicin, Peak 7}

4-Methoxyglucobrassicin, Peak 8 Glucobrassicanapin. HPLC profiles of advanced backcross plants, $\mathrm{R} \times \mathrm{C} 27(20)(23)-25$ and $\mathrm{R} \times \mathrm{C} 27(20)(10)-48$ displayed reduction in $5 \mathrm{C}$ aliphatic glucosinolates, gluconapoleiferin, glucoalyssin, and glucobrassicanapin. 


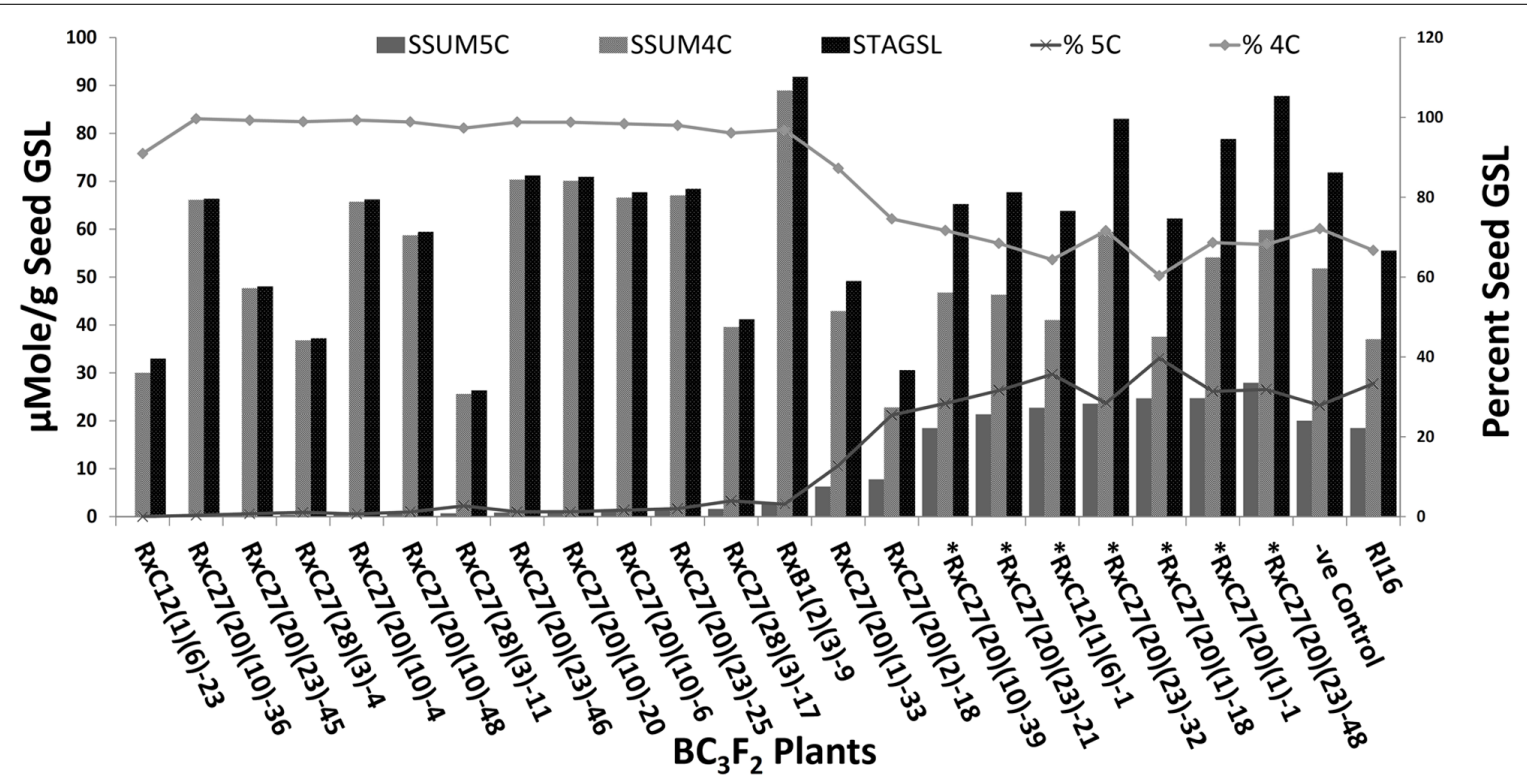

FIGURE 5 | Percent seed total aliphatic glucosinolates (STGSL), seed sum of $4 \mathrm{C}$ GSL (SSUM4C), and seed sum of $5 \mathrm{C}$ GSL (SSUM5C) in $\mathrm{BC}_{\mathbf{3}} \mathrm{F}_{\mathbf{2}}$ plants of RI16 recurrent parent. Asterick "* " represents $B C_{3} F_{2}$ plants with both SCAR markers specific to the A and C-genome. -Ve Control represents $\mathrm{BC}_{3} \mathrm{~F}_{2}$ plant with A-genome specific and without $\mathrm{C}$-genome specific SCAR maker

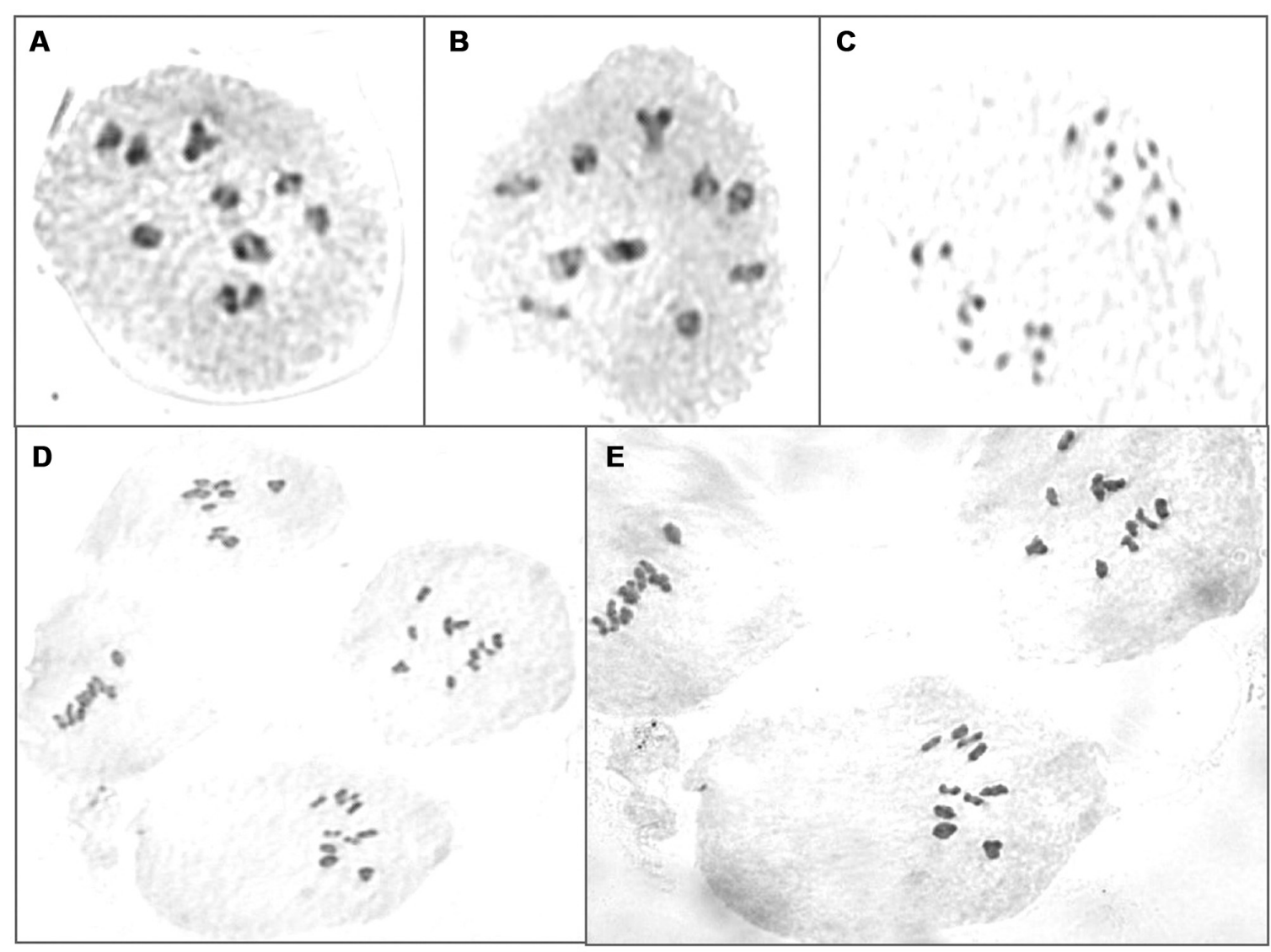

FIGURE 6 | Chromosome counting of $\mathrm{PMCs}$ in $\mathrm{BC}_{3} \mathrm{~F}_{3}$ plants which reduced $\mathbf{5 C}$ aliphatic glucosinolates. $(\mathbf{A}, \mathbf{B})$ Meiotic division at late prephase

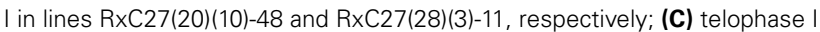

of meiotic division in line RxC27(20)(2)-18; (D,E) metaphase I of meiotic division in lines $\mathrm{R} \times \mathrm{C} 27(20)(23)-25$ and $\mathrm{R} \times \mathrm{C} 12(1)(6)-23$ respectively. 
also reported (Chen et al., 1992; Mikkelsen et al., 1996; Leflon et al., 2006). Homoeologous recombination and alien chromosome transmission rates depend on chromosome identity and meiotic behavior, resulting in varied alien chromosome transmission rates in different digenomic hybrids (Leflon et al., 2006). In this study, varied GSL-ELONG ${ }^{-}$marker transmission rates (4-79\%) were observed in backcross progenies, this suggested variable homoeologous recombination events. This was in accordance with the previous studies reported in Brassica and other crop species. Heneen and Jørgensen (2001) reported variable random amplified polymorphic DNA (RAPD) marker transmission frequencies in aneuploid progenies of $B$. rapa $\times$ B. alboglabra. Kaneko et al. (2003) reported variable marker transmission rates ranging from 26 to $44 \%$ in three consecutive generations of Raphanus sativus possessing monosomic additional chromosomes of B. rapa. Similarly, Shigyo et al. (2003) reported 9- 49\% transmission rates of alien chromosomes in eight Allium monosomic addition lines. Ali et al. (2001) reported transmission rates from 0 to $32 \%$ for chromosome 9 and from 14 to $88 \%$ for chromosome 6 of monosomic tomato chromosome addition lines in the cultivated potato. This suggests that different alien chromosomes have very substantial transmission rates in different crop species. Transmission rates appear to be higher through female parents and for the larger chromosomes (Garriga-Calderé et al., 1998).

Functional gene-based trait introgression has been reported in many studies of crosses between $B$. napus, B. oleracea, or $B$. alboglabra with B. rapa (Guo et al., 1990; Cheng et al., 1994; Heath et al., 1994). However, in B. rapa, this is the first report of homoeologous recombination and gene replacement of a functional locus in the A-genome by a non-functional C-genome specific allele. Gene replacement has led to reduction of $5 \mathrm{C}$ aliphatic glucosinolates in advanced backcross progenies. Replacement of large or small effect loci might have variable contributions on individual and total aliphatic glucosinolate content due to the existence of multiple loci for the BraGSL-ELONG gene in the A-genome. Four and three BraGSL-ELONG loci were integrated for glucosinolate side chain elongation gene by Bisht et al. (2009) in the A-genome of B. juncea and by Geng et al. (unpublished) in B. rapa, respectively. In addition, comparative sequence analysis of Arabidopsis glucosinolate biosynthesis genes with the whole genome sequence dataset of B. rapa ssp. pekinensis cv. chiifu, Wang et al. (2011) revealed three loci for BraMAM1 and four loci for BraMAM3 for side chain elongation genes (BraGSL-ELONG). This suggests existence of genetic complexity for glucosinolate side chain elongation pathway in B. rapa. Availability of genome and gene specific molecular markers with known gene function for glucosinolate biosynthesis pathway, breeding would be enhanced for specific glucosinolate profiles and contents in rapeseed and vegetable Brassica species. In the quantitative trait locus (QTL) mapping study for glucosinolates in B. rapa, Geng et al. (unpublished) identified a single major QTL for $5 \mathrm{C}$ aliphatic glucosinolates on linkage group A3 linked with the SCAR marker, BraMAM1-1. Our results are coherent with those findings and indicate that absence of BraMAM1-1 marker in the A-genome lack 5C aliphatic glucosinolates. This suggests that a major BraGSL-ELONG locus which elongates glucosinolate side chain for $5 \mathrm{C}$ aliphatic glucosinolate biosynthesis is located on chromosome $\mathrm{A} 3$ in the A-genome of B. rapa. On the other hand, no QTL detected on linkage group A9 suggested that BraGSL-ELONG locus on A9 may not play an important role in the biosynthesis of $5 \mathrm{C}$ aliphatic glucosinolates in the Chinese cabbage DH line, RI16 used in this study.

Glucosinolate profiles of 15 progenies which reduced 5C aliphatic glucosinolates also displayed increased in $4 \mathrm{C}$ aliphatic glucosinolates (Figure 5). Similar glucosinolate contents were reported by Liu etal. $(2010,2012)$ through silencing BnGSLELONG and Bn-GSL-ALK gene families in B. napus. These results suggested lack of functional genes at in some steps of chain reactions results in the accumulation of the precursors of glucosinolates in the biosynthesis pathway. For example, in side chain elongation, lack of functional BraGSL-ELONG locus/loci for $5 \mathrm{C}$ or $4 \mathrm{C}$ aliphatic glucosinolates would accumulate $4 \mathrm{C}$ or $3 \mathrm{C}$ aliphatic glucosinolates. In this study, other BraGSL-ELONG loci might have some roles in the biosynthesis of aliphatic glucosinolates including 5C aliphatic glucosinolates, which had not been replaced and resulted in variation of total aliphatic glucosinolate contents in different backcross families. The backcross progenies with random introgression of non-functional allele did not change aliphatic glucosinolate content.

Loss of the markers for the alien chromosome or chromosomal fragment was observed in backcross progenies for GSL-ELONG ${ }^{-}$ gene. This loss might be due to the random inclusion of the alien chromosome into the gametes during meiosis. Retention of the marker would then depend on the specific gametes involved during fertilization of backcrosses. Findings also reported loss of markers for QTL or genes in marker assisted backcross selection in crop species (Sebolt et al., 2000; Ramchiary et al., 2007; Szadkowski et al., 2010). In advanced backcross progenies, significance segregation distortion for GSL-ELONG ${ }^{-}$markers was observed. Similar studies reported for marker distortion to non-Mendelian segregation in Brassica and wheat (Hu and Quiros, 1991; Ceoloni et al., 1996; Marais et al., 2010; Niu et al., 2011). This is a common feature associated in the breeding with most genetic background carrying alien chromosome.

Replacement or introgression of the GSL-ELONG ${ }^{-}$locus in these backcross progenies would be confirmed by additional backcrossing and sequencing the genomic regions of the replaced genes. Alternatively, resynthesized B. napus line would be developed through a cross between a $B$. rapa line with trace amount of 5C GSL and B. oleracea white cauliflower which lacks 4C and 5C aliphatic glucosinolates. The Chinese cabbage lines with reduced 5C aliphatic glucosinolates achieved in this study could be used for manipulation of glucosinolate profiles in B. napus, B. juncea, and other B. rapa accessions.

\section{ACKNOWLEDGMENTS}

This research project was supported by the Genome Canada/Genome Prairie/Genome Alberta for the project "Designing Oilseeds for Tomorrow's Markets" and by Bunge Canada, DL Seeds, the Natural Sciences Engineering Research Council of Canada (NSERC), and the Manitoba Canola Growers Association in an IRC program. 


\section{REFERENCES}

Ali, S. N. H., Ramanna, M. S., Jacobsen, E., and Visser, R. G. F. (2001). Establishment of a complete series of a monosomic tomato chromosome addition lines in the cultivated potato using RFLP and GISH analyses. Theor. Appl. Genet. 103, 687-695.

Attia, T., and Röbbelen, G. (1986). Cytogenetic relationship within cultivated Brassica analyzed in amphihaploids from the three diploid ancestors. Can. J. Genet. Cyto. 28, 323-329.

Attia, T., and Röbbelen, G. (1987). Digenomic triploids for an assessment of chromosome relationships in the cultivated diploid Brassica species. Genome 29, 326-330.

Banga, S. S. (1988). C-genome chromosome substitution lines in Brassica juncea (L.) Coss. Genetica 77, 81-84.

Bisht, N. C., Gupta, V., Ramchiary, N., Sodhi, Y. S., Mukhopadhyay, A., Arumugam, N., et al. (2009). Fine mapping of loci involved with glucosinolate biosynthesis in oilseed mustard (Brassica juncea) using genomic information from allied species. Theor. Appl. Genet. 118, 413-421.

Brown, P. D., Tokuhisa, J. G., Reichelt, M., and Gershenzon, J. (2003). Variation of glucosinolate accumulation among different organs and developmental stages of Arabidopsis thaliana. Phytochemistry 62, 471-481.

Ceoloni, C., Biagetti, M., Ciaffi, M., Forte, P., and Pasquini, M. (1996) Wheat chromosome engineering at the $4 \times$ level: the potential of different alien gene transfers into durum wheat. Euphytica 89, 87-97.

Chen, B. Y., Simonsen, V., LannerHerrera, C., and Hennen, W. K. (1992). A Brassica campestrisB.alboglabra addition line and its use for gene mapping, intergenomic gene transfer and generation of trisomics. Theor. Appl. Genet. 84, 592-599.

Cheng, B. F., Chen, B. Y., and Heneen, W. K. (1994). Addition of Brassica alboglabra Bailey chromosomes to $B$. campestris $\mathrm{L}$. with special emphasis on seed colour. Heredity 73, 185-189.

Compos de Quiros, H., Magrath, R., McCallum, D., Kroymann, J., Schnabelrauch, D., Mitchell-Olds, T., et al. (2000). $\alpha$-Keto acid elongation and glucosinolate biosynthesis in Arabidopsis thaliana. Theor. Appl. Genet. 101, 429-437.

Dover, G. A., and Riley, R. (1972). Prevention of pairing of homoeologous meiotic chromosomes of wheat by an activity of supernumerary chromosomes of Aegilops. Nature 24, 159-161.

Feldman, M. (1966). The effect of chromosomes 5B, 5D, and $5 \mathrm{~A}$ on chromosomal pairing in Triticum aestivum. Proc. Natl. Acad. Sci. U.S.A. 55, 1447-1453.

Gaeta, R. T., Pire, J. C., Iniguez-Luy, F., Leon, E., and Osborn, T. C. (2007) Genomic changes in resynthesized Brassica napus and their effect on gene expression and phenotypic variation. Plant Cell 16, 3403-3417.

Gao, M., Li, G., Yang, B., McCombie, W. R., and Quiros, C. F. (2004). Comparative analysis of a Brassica BAC clones containing several major aliphatic glucosinolate genes with its corresponding Arabidopsis sequence. Genome 47, 666-679.

Garriga-Calderé, F., Huigen, D. J., Angrisano, A., Jacobsen, E., and Ramanna, M. S. (1998). Transmission of alien tomato chromosomes from $\mathrm{BC} 1$ to $\mathrm{BC} 3$ progenies derived from backcrossing potato $(+)$ tomato fusion hybrids to potato: the selection of single additions for seven different tomato chromosomes. Theor. Appl. Genet. 96, 155-163.

Guo, Z. H., Dickson, M. H., and Hunter, J. E. (1990). "Brassica napus sources of resistance to black rot in crucifers and inheritance of resistance," in Proceedings of the 6th Crucifer Genetics Workshop (Ithaca, NY: Cornell University), 154-155.

Heath, D. W., Earle, E. D., and Dickson, M. H. (1994). Introgressing cold-tolerant Ogura cytoplasms from rapeseed into Pak choi and Chinese cabbage. Hortic. Sci. 29, 202-203.

Heneen, W. K., and Jørgensen, R. B. (2001). Cytology, RAPD, and seed colour of progeny plants from Brassica alboglabra aneuploids and development of monosomic addition lines. Genome 44, 1007-1021.

$\mathrm{Hu}$, J., and Quiros, C. F. (1991). Molecular and cytological evidence of deletions in alien chromosomes for two monosomic addition lines of Brassica campestris-oleracea. Theor. Appl. Genet. 90, 258-262.

Jenczewski, E., Eber, F., Grimaud, A., Huet, S., Lucas, M. O., Monod, H., etal. (2003). PrBn, a major gene controlling homeologous pairing in oilseed rape (Brassica napus) haploids. Genetics 164, 645-653.

Kaneko, Y., Yano, H., Bang, S. W., and Matsuzawa, Y. (2003). Genetic stability and maintenance of Raphanus sativus lines with an added Brassica rapa chromosome. Plant Breed. 122, 239-243.

King, I. P., Forster, B. P., Law, C. C., Cant, K. A., Orford, S. E., Gorham,
J., etal. (1997). Introgression of salt-tolerance genes from Thinopyrum bessarabicum into wheat. New Phytol. 137, 75-81.

Kliebenstein, D. J., Gershenzon, J., and Mitchell-Olds, T. (2001a). Comparative quantitative trait loci mapping of aliphatic, indole and benzylic glucosinolate production in Arabidopsis thaliana leaves and seeds. Genetics $159,359-370$

Kliebenstein, D. J., Kroymann, J., Brown, P., Figuth, A., Pedersen, D., Gershenzon, J., et al. (2001b) Genetic control of natural variation in Arabidopsis glucosinolate accumulation. Plant Physiol. 126, 811-825.

Kliebenstein, D. J., Lambrix, V. M., Reichelt, M., Gershenzon, J., and Mitchell-Olds, T. (2001c). Gene duplication in the diversification of secondary metabolism: tandem 2-oxoglutarate-dependent dioxygenases control glucosinolate biosynthesis in Arabidopsis. Plant Cell 13, 681-693.

Kuraparthy, V., Sood, S., and Gill, B. S. (2009). Molecular genetic description of the cryptic wheat-Aegilops geniculata introgression carrying rust resistance genes Lr57 and Yr40 using wheat ESTs and synteny with rice. Genome 52, 1025-1036.

Leflon, M., Eber, F., Letanneur, J. C., Chelysheva, L., Coriton, O., Huteau, V., et al. (2006). Pairing and recombination at meiosis of Brassica rapa (AA) $\times$ Brassica napus (AACC) hybrids. Theor. Appl. Genet. 113, 1467-1480.

Li, G., and Quiros, C. F. (2001). Sequence-related amplified polymorphism (SRAP), a new marker system based on a simple PCR reaction: its application to mapping and gene tagging in Brassica. Theor. Appl. Genet. 103, 455-461.

Li, G., and Quiros, C. F. (2002). Genetic analysis, expression and molecular characterization of Bo-GSLELONG, a major gene involved in the aliphatic glucosinolate pathway of Brassica species. Genetics 162, 1937 1943.

Li, G., and Quiros, C. F. (2003). In planta side-chain glucosinolate modification in Arabidopsis by introduction of dioxygenase Brassica homolog BoGSL-ALK. Theor. Appl. Genet. 106, 1116-1121.

Li, J., Hansen, B. G., Ober, J. A., Kliebenstein, D. J., and Halkier, B. A. (2008). Subclade of flavin-monooxygenases involved in aliphatic glucosinolate biosynthesis. Plant Physiol. 148, 1721-1733.

Liu, Z., Hammerlindl, J., Keller, W. McVetty, P. B. E., Daayf, F., Quiros,
C. F., et al. (2010). MAM gene silencing leads to the induction of $\mathrm{C} 3$ and reduction of $\mathrm{C} 4$ and $\mathrm{C} 5$ side-chain aliphatic glucosinolates in Brassica napus. Mol. Breed. 27, 467-478.

Liu, Z., Hirani, A. H., McVetty, P. B. E., Daayf, F., Quiros, C. F., and Li, G. (2012). Reducing progoitrin and enriching glucoraphanin in B. napus seeds through silencing of the GSLALK gene family. Plant Mol. Biol. 79, 179-189.

Marais, G. F., Kotze, L., and Eskteen, A. (2010). Allosyndetic recombinants of the Aegilops peregrina derived Lr59 translocation in common wheat. Plant Breed. 129, 356361.

Martinez, M. N., Cuñado, N., Carcelén, N., and Romero, C. (2001). The Ph1 and $\mathrm{Ph} 2$ loci play different roles in the synaptic behaviour of hexaploid wheat Triticum aestivum. Theor. Appl. Genet. 103, 398-405.

McGrath, J. M., and Quiros, C. F. (1990). Generation of alien chromosome addition lines from synthetic Brassica napus: morphology, cytology, fertility, and chromosome transmission. Genome 33, 374-383.

Mikkelsen, T. R., Jensen, J., and Jorgensen, R. B. (1996). Inheritance of oilseed rape (Brassica napus) RAPD markers in a backcross progeny with Brassica campestris. Theor. Appl. Genet. 92, 492-497.

Navabi, Z. K., Strelkov, S. E., Good, A. G., Thiagarajah, M. R., and Rahman, M. H. (2010). Brassica B-genome resistance to stem rot (Sclerotinia sclerotiorum) in a double haploid population of Brassica napus x Brassica carinata. Can. J. Plant Pathol. 32, 237-246.

Nicolas, S. D., Leflon, M., Monod, H., Eber, F., Coriton, O., Huteau, V., et al. (2009). Genetic regulation of meiotic cross-overs between related genomes in Brassica napus haploid and hybrids. Plant Cell 21, 373-385.

Niu, Z., Klindworth, D. L., Friesen, T. L., Chao, S., Jin, Y., Cai, X., et al. (2011). Targeted introgression of a wheat stem rust resistance gene by DNA marker-assisted chromosome engineering. Genetics 187, 1011-1021.

Parkin, I. A. P., Gulden, S. M., Sharpe, A. G., Lukens, L., Trick, M., Osborn, T. C., et al. (2005). Segmental structure of the Brassica napus genome based on comparative analysis with Arabidopsis thaliana. Genetics 171, 765-781.

Parkin, I. A. P., Sharpe, A. G., Keith, D. J., and Lydiate, D. J. (1995). Identification of the $\mathrm{A}$ and $\mathrm{C}$ genomes of the amphidiploid Brassica napus (oilseed rape). Genome 38, 1122-1131. 
Punjabi, P., Jagannath, A., Bisht, N. C., Padmaja, K. L., Sharma, S., Gupta, V., et al. (2008). Comparative mapping of Brassica juncea and Arabidopsis thaliana using intron polymorphism (IP) markers: homoeologous relationships, diversification and evolution of the A, B and C Brassica genomes. BMC Genomics 9:113. doi: 10.1186/1471-2164-9-113

Ramchiary, N., Bisht, N. C., Gupta, V., Mukhopadhyay, A., Arumugam, N., Sodhi, Y. S., et al. (2007). QTL analysis reveals context-dependent loci for seed glucosinolate trait in the oilseed Brassica juncea: importance of recurrent selection backcross scheme for the identification of 'true' QTL. Theor. Appl. Genet. 116, 77-85.

Sebolt, A. M., Shoemaker, R. C., and Diers, B. W. (2000). Analysis of a quantitative trait locus allele from wild soybean that increases seed protein concentration in soybean. Crop Sci. 40, 14381444.

Sharpe, A. G., Parkin, I. A. P., Keith, D. J., and Lydiate, D. J. (1995).
Frequent non-reciprocal translocations in the amphidiploid genome of oilseed rape. Genome 38, 1112-1121.

Shigyo, M., Wako, T., Kojima, A. Yamauchi, N., and Tshiro, Y. (2003). Transmission of alien chromosomes from selfed progenies of a complete set of Allium monosomic additions: the development of a reliable method for the maintenance of a monosomic addition set. Genome 46, 1098 1103.

Song, K., Lu, P., Tang, K., and Osborn, T. C. (1995). Rapid genome change in synthetic polyploids of Brassica and its implications for polyploidy evolution. Proc. Natl. Acad. Sci. U.S.A. 92, 7719-7723.

Srinivasan, K., Malathi, V. G., Kirti, P. B., Prakash, S., and Chopra, V. I. (1998). Generation and characterization of monosomic chromosome addition lines of Brassica campestrisB. oxyrrhina. Theor. Appl. Genet. 97, 976-981.

Szadkowski, E., Eber, F., Huteau, V., Lodé, M., Huneau, C., Belcram, H., etal. (2010). The first meiosis of resynthesized Brassica napus, a genome blender. New Phytol. 186, 102-112.

Textor, S., de Kraker, J. W., Hause, B., Gershenzon, J., and Tokuhisa, J. G. (2007). MAM3 catalyzes the formation of all aliphatic glucosinolate chain lengths in Arabidopsis. Plant Physiol. 144, 60-71.

Wang, H., Wu, J., Sun, S., Liu, B., Cheng, F., Sun, R., et al. (2011). Glucosinolate biosynthesis genes in Brassica rapa. Gene 487, 135-142.

Wang, X., Wang, H., Wang, J., Sun, R., Wu, J., Liu, S., et al. (2011). The genome of the mesopolyploid crop species Brassica rapa. Nat. Genet. 43 , 1035-1039.

Wroblewski, T., Coulibaly, S., Sadowski, J., and Quiros, C. F. (2000). Variation and phylogenetic utility of the Arabidopsis thaliana Rps2 homolog in various species of the tribe Brassiceae. Mol. Phylogenet. Evol. 16, 440-448.

Conflict of Interest Statement: The authors declare that the research was conducted in the absence of any commercial or financial relationships that could be construed as a potential conflict of interest.

Received: 28 November 2012; accepted: 28 February 2013; published online: 25 March 2013

Citation: Hirani AH, Zelmer $C D$, McVetty PBE, Daayf $F$ and Li G (2013) Homoeologous GSL-ELONG gene replacement for manipulation of aliphatic glucosinolates in Brassica rapa L. by marker assisted selection. Front. Plant Sci. 4:55. doi: 10.3389/fpls.2013. 00055

This article was submitted to Frontiers in Plant Genetics and Genomics, a specialty of Frontiers in Plant Science.

Copyright (c) 2013 Hirani, Zelmer, McVetty, Daayf and Li. This is an openaccess article distributed under the terms of the Creative Commons Attribution License, which permits use, distribution and reproduction in other forums, provided the original authors and source are credited and subject to any copyright notices concerning any third-party graphics etc. 